\title{
Angiographic Demonstration of Neoangiogenesis After Intra-arterial Infusion of Autologous Bone Marrow Mononuclear Cells in Diabetic Patients With Critical Limb Ischemia
}

\author{
Rafael Ruiz-Salmeron,* Antonio de la Cuesta-Diaz, ${ }^{*}$ Manuel Constantino-Bermejo, ${ }^{*}$ \\ Immaculada Pérez-Camacho,* Francisco Marcos-Sánchez,* Abdelkrim Hmadcha, $\dagger+$ and Bernat Soria $\dagger \neq$ \\ *Hospitales Universitarios San Lázaro and Virgen Macarena, Sevilla, Spain \\ †Centro Andaluz de Biología Molecular y Medicina Regenerativa (CABIMER), Sevilla, Spain \\ †CIBER de Diabetes y Enfermedades Metabólicas Asociadas (CIBERDEM), Barcelona, Spain
}

\begin{abstract}
Critical limb ischemia in diabetic patients is associated with high rates of morbidity and mortality. Suboptimal responses to the available medical and surgical treatments are common in these patients, who also demonstrate limited vascular homeostasis. Neovasculogenesis induced by stem cell therapy could be a useful approach for these patients. Neovasculogenesis and clinical improvement were compared at baseline and at 3 and 12 months after autologous bone marrow-derived mononuclear cell (BMMNC) transplantation in diabetic patients with peripheral artery disease. We conducted a prospective study to evaluate the safety and efficacy of intra-arterial administration of autologous BMMNCs $\left(100-400 \times 10^{6}\right.$ cells $)$ in 20 diabetic patients with severe below-the-knee arterial ischemia. Although the time course of clinical effects differed among patients, after 12 months of follow-up all patients presented a notable improvement in the Rutherford-Becker classification, the University of Texas diabetic wound scales, and the Ankle-Brachial Index in the target limb. The clinical outcome was consistent with neovasculogenesis, which was assessed at 3 months by digital subtraction angiography and quantified by MetaMorph software. Unfortunately, local cell therapy in the target limb had no beneficial effect on the high mortality rate in these patients. In diabetic patients with critical limb ischemia, intra-arterial perfusion of BMMNCs is a safe procedure that generates a significant increase in the vascular network in ischemic areas and promotes remarkable clinical improvement.
\end{abstract}

Key words: Bone marrow-derived mononuclear cells (BMMNCs); Peripheral artery disease (PAD); Critical limb ischemia (CLI); Ankle-brachial index (ABI); Digital subtraction angiography (DSA); Below the knee

\section{INTRODUCTION}

Peripheral artery disease (PAD) is a common and severe complication of diabetes mellitus and shows high rates of short-term morbidity and mortality. PAD in diabetic patients shows a distinctive pattern with occlusive arterial lesions that are typically located distally below the knee (BTK); this limits the possibility of successful mechanical revascularization by either surgical or endovascular methods $(6,7)$. Neovasculogenesis, which is the development of a new vascular network, is a physiological response to chronic ischemia and comprises two different processes: angiogenesis and arteriogenesis. Angiogenesis consists of the sprouting of capillaries and the formation of a capillary network that grows within an ischemic area. In contrast, arteriogenesis is the process of arteriolar enlargement and the formation of collateral vessels that connect preocclusive arteries to the diseased intraischemic arteries (29). Both mechanisms of compensatory neovasculogenesis are impaired in diabetic patients due to endothelial progenitor cell dysfunction; this impairment explains the early extensive and accelerated process of vascular complications in diabetes mellitus $(12,20,31)$. The number of peripheral endothelial progenitor cells in both type 1 and type 2 diabetic patients is decreased by more than $40 \%$ and is correlated with an increase in glycosylated hemoglobin (HbA1c) $(11,20)$. Subsequently, PAD is associated with a very low number of endothelial progenitor cells in peripheral blood (11).

Stem cell revascularization therapy for the treatment of diabetic nonrevascularizable PAD is a recent approach

Received June 2, 2010; final acceptance December 29, 2010. Online prepub date: April 1, 2011.

Address correspondence to Bernat Soria, M.D., Ph.D., Centro Andaluz de Biología Molecular y Medicina Regenerativa (CABIMER), Américo Vespucio s/n, 41092 Sevilla, Spain. Tel: (+34) 954468004; Fax: (+34) 954461664; E-mail: bernat.soria@cabimer.es 
with encouraging preliminary results $(13,15,30)$ : clinical improvement and the rescue of the Ankle-Brachial Index (ABI) have been described in the majority of studies. However, the optimum dose, source, and route of administration (intramuscular, intra-arterial, or combined) are outstanding questions, which remain to be addressed $(24,28)$. In addition, most of the studies conducted to date are based on surrogate endpoints that reflect changes in limb perfusion and very few reports are available that consist of angiographic demonstration of increased vascularization after cell therapy. To address this, cell implantation would require ex vivo cell labeling $(5,8,22)$, which is difficult to reconcile with good medical practice principles (32). Furthermore, an increase in HbA1c correlates with a decrease in endothelial progenitors $(11,20)$, which means that diabetic patients with HbA1cs above $6.5 \%$ were excluded from previous studies.

The rationale of this study was that intra-arterial infusions of autologous bone marrow-derived mononuclear cells (BMMNCs), which contain endothelial progenitors, that are perfused locally at severely diseased vascular beds in the lower limb could promote an early and effective development of neovasculogenesis in diabetic patients with critical limb ischemia (CLI).

\section{MATERIALS AND METHODS}

We conducted a prospective single-center study (ClinicalTrials.gov Identifier: NCT-00872326), phase IIIa, that aimed to assess the safety and efficacy of intraarterial administration of BMMNCs in diabetic patients with CLI. This clinical trial was promoted by Fundación Progreso y Salud under a noncommercial investigatordriven grant and was approved by the local institutional review boards, the regional Andalusian Ethics Committee, and the Andalusian Initiative for Advanced Therapies (9).

\section{Patient Inclusion}

Our population sample was composed of 20 patients with severe limb ischemia, with no options of revascularization, who were treated with autologous BMMNC preparation. In the case of bilateral limb ischemia, the target limb used in the study was the more severely affected limb. All patients provided written informed consent and fulfilled the inclusion criteria (Table 1). Of these patients, $11(55 \%)$ had undergone failed attempts of revascularization using PTA/stents or bypass in the ischemic limb and 9 (45\%) presented no run-off and were not suitable for revascularization. CLI was diagnosed according to the recommendations of the current TransAtlantic Inter-Society Consensus (TASC) (23).

Assessment of the peripheral circulation of patients was performed at baseline and at 3 and 12 months, respectively. This consisted of a complete noninvasive
Table 1. Population Characteristics (Baseline Data)

\begin{tabular}{lc}
\hline Parameters & Value \\
\hline Age (53-75 years old) & $64.5 \pm 5.8$ \\
Male gender (\%) & $18(90 \%)$ \\
Diabetes (years since diagnosed) & $20.8 \pm 5.8$ \\
Risk factors & \\
Dislipidemia (\%) & $11(55 \%)$ \\
Hypertension (\%) & $15(75 \%)$ \\
Smokers (\%) & $13(65 \%)$ \\
Coronary artery disease (\%) & $9(55 \%)$ \\
HbA1c (\%) & $7.7 \pm 1.0$ \\
Target limb findings & \\
Location: Right (\%)/left & $14(70 \%) / 6$ \\
Rutherford Becker & \\
Category 4 & $3(15 \%)$ \\
Category 5 & $11(55 \%)$ \\
Category 6 & $6(30 \%)$ \\
Failed revascularization intervention & \\
PTA/stent & $10(50 \%)$ \\
Bypass & $1(5 \%)$ \\
No run off & $9(45 \%)$ \\
Minor amputations & \\
Transmetatarsal & \\
Chopart's & $5(25 \%)$ \\
BTK occlusion & $1(5 \%)$ \\
3 vessels & \\
2 vessels & \\
1 vessel & $(40.74 \pm 10.59$ \\
tcpO $(m m H g) *$ & $0.46 \pm 0.19$ \\
ABI & $8(40 \%)$ \\
Ulcers (\%) & \\
\hline
\end{tabular}

Values are shown as mean \pm SD for 20 patients who fulfilled the following inclusion criteria: age $\leq 75$ years old, diabetes (type 1 or 2 ), and severe ischemia (Rutherford-Becker categories 4/6) of at least one lower limb due to extensive below-the-knee arterial disease not suitable to revascularization. Revascularization interventions were performed 1-2 years before bone marrow-derived mononuclear cell (BMMNC) transplantation. PTA, percutaneous transluminal angioplasty; BTK, below the knee; HbA1c, glycosylated hemoglobin; tcpO $\mathrm{O}_{2}$, transcutaneous partial oxygen pressure; ABI, Ankle-Brachial Index.

*Six patients with tcpO $\mathrm{O}_{2}<30 \mathrm{mmHg}(22 \pm 4 \mathrm{mmHg})$.

vascular work-up, which included measurement of systolic blood pressure at both the anterior and posterior tibial arteries, measurement of ABI, which is the quotient of the highest ankle pressure and the highest brachial systolic blood pressure and imaging studies that consisted of conventional intra-arterial digital subtraction angiography. Transcutaneous partial oxygen tissue pressures $\left(\mathrm{tcpO}_{2}\right)$ in the supine position were recorded using an oxygen monitor (TCM400 Radiometer, Copenhagen, Denmark). To assess the severity of limb ischemia, we followed the classification system proposed by Rutherford et al. (26); wounds were graded and were staged according to University of Texas Diabetic Wound 
Classification System (18). All patients were evaluated on a case-by-case basis by a dedicated multidisciplinary vascular team that included interventional radiologists and vascular surgeons.

\section{Autologous BMMNC Preparation}

The process of BMMNC preparation and administration was performed completely within the catheterization laboratory surgical room. After mild sedation and local anesthesia, the iliac crest was punctured and aspirated to obtain $60 \mathrm{ml}$ of bone marrow preparation. This sample was diluted in $40 \mathrm{ml}$ of heparinized saline (20 UI nonfractionated heparin/ml). BMMNCs were separated with a Ficoll density gradient (Amersham Pharmacia Biotech, Uppsala, Sweden) and washed in PBS (Sigma, St. Louis, MO, USA). Prior to the administration of the BMMNCs, the number of mononuclear cells and their viability was determined and a sample of $0.5 \mathrm{ml}$ was obtained for determination of the percentage of CD34 cells by flow cytometry analysis (Citomics FC 500 Beckman-Coulter). Finally, BMMNCs were filtered through a cell strainer and diluted in $20 \mathrm{ml}$ of saline to fill a 50-ml syringe that was kept sealed until administration.

\section{Intra-arterial Administration of BMMNCs}

While the BMMNCs were being processed, target limb arteries were selectively cannulated through a transfemoral or transradial approach with an over-thewire catheter balloon that was advanced as distally as possible and positioned proximal to the occlusive vascular lesions, usually at the distal femoral or popliteal artery. At this point, the balloon was inflated to block antegrade blood flow and the BMNMCs were slowly infused for $3 \mathrm{~min}$. After infusion, the balloon was deflated and antegrade blood flow was restored. The number of BMMNCs obtained ranged from $113.7 \times 10^{6}$ to $434.5 \times 10^{6}$ (mean $\left.266.2 \pm 81.89 \times 10^{6}\right)$. The amount of $\mathrm{CD}^{+} 4^{+}$cells was $1.73 \pm 0.43 \%$, which resulted in a mean infusion of $4.37 \pm 1.54 \times 10^{6} \mathrm{CD}^{2} 4^{+}$cells (ranging from $2.14 \times 10^{6}$ to $7.81 \times 10^{6}$ cells). The site of BMMNC infusion was distal femoral artery in 1 patient, popliteal artery in 13 patients, and BTK in 6 patients. In 6 patients, the procedure was performed using a transradial approach that required extra-large over-the-wire balloons of 200-cm length.

\section{Evaluation of BMMNC Transplantation Efficacy}

The efficacy of BMMNC transplantation was assessed by the development of neovascularization downstream of the site of cell infusion. The primary endpoint was the angiographic evaluation of neovascularization, with quantification of vascular network growth at the 3month follow-up. Secondary endpoints were the evalua- tion of ABI changes at the 3-month follow-up and the changes in the Rutherford-Becker and University of Texas classifications during the course of the study compared to baseline values (obtained at the time of infusion).

\section{Angiographic Quantification of Neovascularization}

For each patient, a comparison of lower limb digital subtraction angiography (DSA) images between baseline and at the 3-month follow-up was performed. Both DSA acquisitions were performed by a vascular fluoroscopic imaging system (Infinix, Toshiba, Japan) and were focused on the BTK area; measurements were obtained under the same acquisition and procedural parameters (level of injection and contrast flow). DSA acquisitions were sent to a core-lab (CABIMER, Seville Spain) for quantitative analysis; a common area was selected for quantification (Fig. 1A). Quantitative analysis of the resulting images was performed using MetaMorph $\AA$ v.6.3 using the Angiogenesis Tube Formation application module. Minimum and maximum width vessels were initially empirically chosen to fit angiographic value ranges from 0.5 to $6 \mathrm{~mm}$ (thinnest to thickest tubule, respectively). Analysis was performed using four intensity values above the local background (400, 600, 800, and 1000 gray levels). As shown in Figure 1B, the final process of quantification generated a segmented image [16-bit autoscaled image where a value of 2 (white) represents the vessels and a value of 1 (green) represents the nodes]. The numeric results are presented as mean \pm SEM of the intensity values above local background for each parameter. Statistical significance was assessed by using a paired difference mean of each parameter pairedsamples $t$-test (sig. two-tailed). The assessment of the vascular network was focused on the measurement of its extension and density: the extension of vascularity was the sum of the arterial length (total tubule length) or the arterial area (total tubule area); the vascular density, which expressed the sprouting and vascular network formation, was measured by counting the number of segments (total number of vessel segments connecting branch points and/or ends) and the number of branch points (total number of junctions connecting segments). The schematic illustration of those parameters is indicated in Figure 1C. Neovascularization was characterized as a significant increment of extension and/or density of the vascular network at the 3-month follow-up compared to baseline.

\section{Safety Assessment}

The safety assessment checked for possible adverse events related to the intra-arterial infusion of BMMNCs, which was initially performed $24 \mathrm{~h}$ after the procedure, focused on the risk of thrombogenic events. These as- 
A
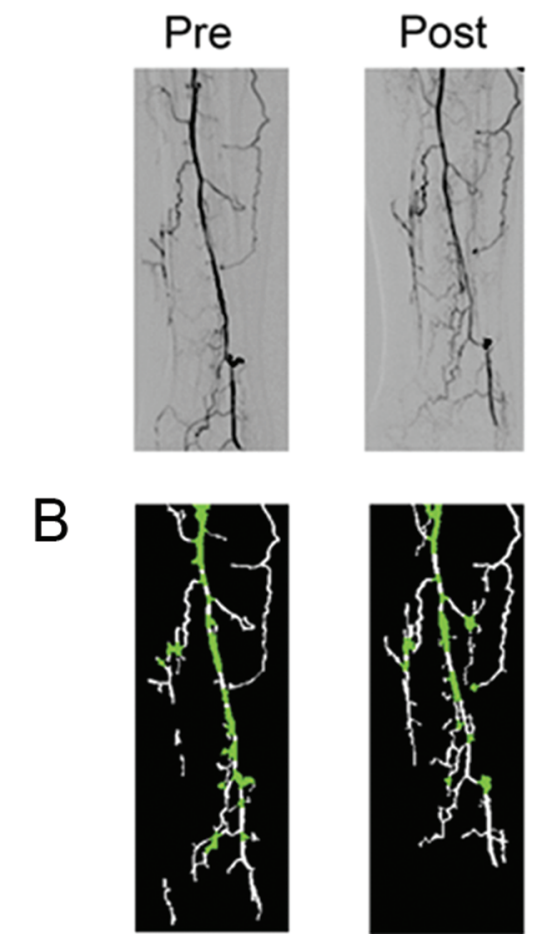

C

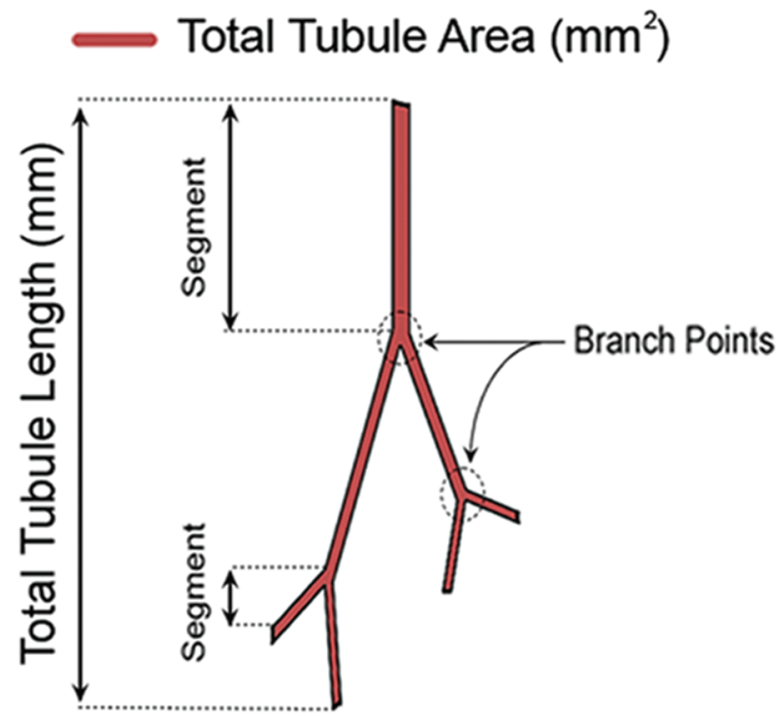

Figure 1. Angiographic quantification steps to assess neovascularization. (A) Baseline (Pre) and 3 month follow-up (Post) identical images from a selected common same area to be quantified. (B) Segmented image generated by MetaMorph ${ }^{\circledR}$ v.6.3 to evaluate the degree of vascularization [tubes are displayed in white and the nodes in green; segments (blue) and the branch points (orange) are not visible]. (C) Schematic illustration of the four parameters selected for the quantification.

sessments were then followed up with planned clinical visits at 1,3 , and 12 months after the procedure; severe adverse events were reported to the promoter of the study.

\section{RESULTS}

\section{Baseline Clinical Characteristics}

Twenty patients (Table 1) average age of $64 \pm 6$ years old (51-75 years old), who consisted of 18 males and 2 females, were included. All but one patient (P13) had type 2 diabetes. Diabetes treatment consisted of insulin in 13 patients (in 2 patients, this was administered in combination with oral antidiabetic agents) and antidiabetic oral agents alone for the remaining 7 patients. The mean glycosylated hemoglobin was $7.7 \pm 1.0 \%$ (ranging from 5.7 to $9.7 \%$ ), which is a value similar to that reported to induce impaired proliferation, adhesion, and incorporation of endothelial progenitor cells into vascular structures (31). The majority of our patients suffered severe microvascular complications: diabetic neuropathy (25) in 17 patients, retinopathy in 12 , and diabetic nephropathy in 4 patients (no patient was undergoing hemodialysis). There was also extensive spread of mac- rovascular disease; 7 patients were referred with symptomatic vascular disease other than PAD (coronary and cerebrovascular) and all the patients presented with bilateral limb symptoms at baseline. The mean ABI results, as an expression of limb perfusion, reflected the severity of the clinical manifestations for both limbs: $0.49 \pm 0.23$ for the right limb and $0.56 \pm 0.17$ for the left one. Selected target lower limbs (14 right and 6 left lower limbs) were severely symptomatic (100\% of patients had Rutherford-Becker category of 4/6), with a mean ABI value of $0.46 \pm 0.19$. In most patients, the contralateral extremities were also affected, although they were less symptomatic. The University of Texas diabetic wound classification showed unhealed ulcers for 11 patients ( 7 grade $\mathrm{C} 3,3$ grade $\mathrm{C} 2$, and 1 grade A2). The remaining 9 patients displayed healed trophic lesions at the start of the trial and target limbs were classified as $\mathrm{C} 1, \mathrm{C} 0$, and $\mathrm{A} 0$, with 3 patients for each category.

\section{Quantitative Assessment of Neovascularization}

Systematic angiographic review to evaluate BTK neovascularization was performed before and 3 months 
after the infusion of BMMNCs for all patients, except for one, who died before angiographic follow-up. Comparison of angiographic images showed a widespread improvement in BTK vascularization (Fig. 2A) downstream of the site of cell administration (Fig. 2B). Vascular improvement presented two patterns, which were usually combined. One pattern was the development of a vascular network, which expanded from the main vessels (tibial anterior, tibial posterior, or peroneal arteries) to the periphery of the calf that was comprised of tapered and highly branched vessels that reached the subcutaneous tissue; the other consisted of an increase in the diameter of collateral preexisting vessels. Another angiographic finding, which was detected in 3 patients (P4, P9, and P13), was the development of a rapid (fistulous) arteriovenous transition, with simultaneous filling of downstream arteries and upstream venous drainage; this unexpected finding was particularly remarkable in one patient (P9), which showed the presence of multiple structures with the appearance of angioma-like structures (defined as a rapid arteriovenous transition during the early phase of arteriography that showed unique or multiple focal contrast-enhanced formations, as assessed by angiographic analysis) (Figure 3A). These patients did not present with any clinical complications at follow-up.

Besides this visual assessment of vascularization, a routine quantitative analysis was performed to assess neovascularization. MetaMorph software was used to evaluate the development of a vascular tree downstream of the site of cell infusion to provide information about the extension of vascularity and the density of the vascular network. Neovascularization was considered as the net improvement in vascular extension and/or the density at the 3-month follow-up compared to baseline. Quantification showed that substantial neovascularization was achieved by the majority of patients: 13 patients $(68 \%)$ at the 3-month follow-up showed an improvement in vascularity with an increase in vascular extension and/or vascular density variables. Regarding variables that measured vascular extension, at the 3month follow-up, there was a significant increase in the overall length of the vessels in 11 patients $(58 \%)$, whereas 10 patients $(53 \%)$ presented with significant increases in total vessel area. Regarding the density of the sprouting network vascularity, at the 3-month follow-up 11 patients $(58 \%)$ presented with significant increases in the total number of vessel segments connecting branch points and/or ends; 10 patients (53\%) presented with significantly increased branch point variables (the total number of junctions connecting segments). Thus, the overall quantification of our population showed a statistically significant increase in vascular extension [total

\section{A}

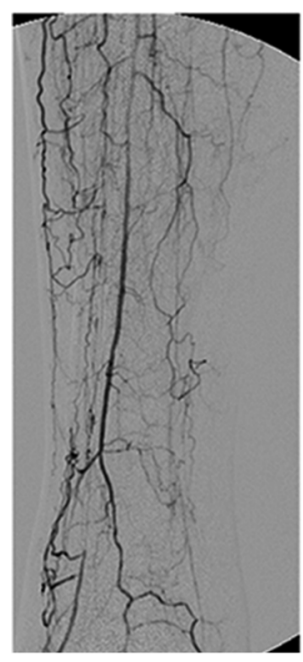

Baseline

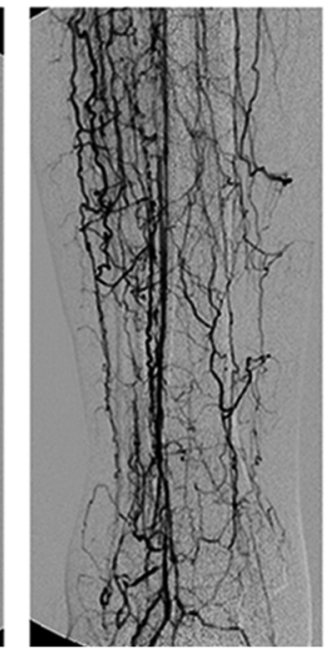

3 months follow-up (early frames)
B
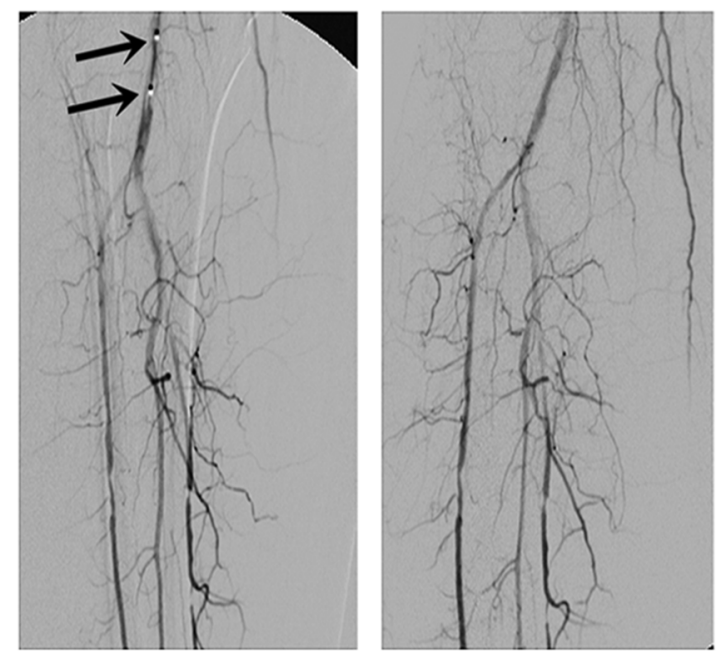

Baseline
3 months follow-up

Figure 2. Angiographic evaluation at 3 months follow-up after autologous bone marrow-derived mononuclear cell (BMMNC) administration. (A) Patient with baseline patency of only peroneal artery presented at 3 month follow-up an outstanding vascular network growth, with collateral arteries enlargement and denser network due to proliferation of new branches. (B) Angiographic image at baseline (left) showing the site of autologous BMMNC administration (black arrows) and at 3 months after (right) where new collateralization of capillary vessels was appreciated. 
A

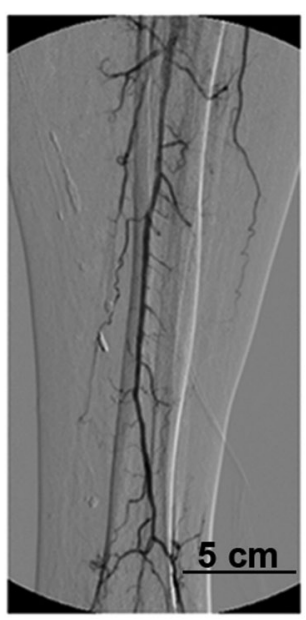

Baseline

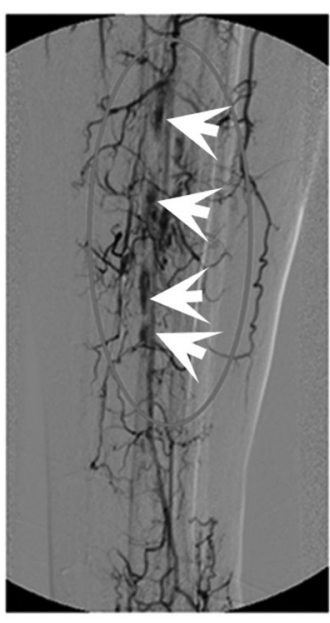

3 months follow-up (early frames)

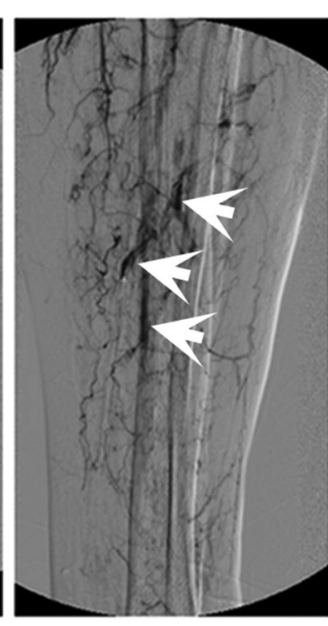

3 months follow-up

(late frames)

B

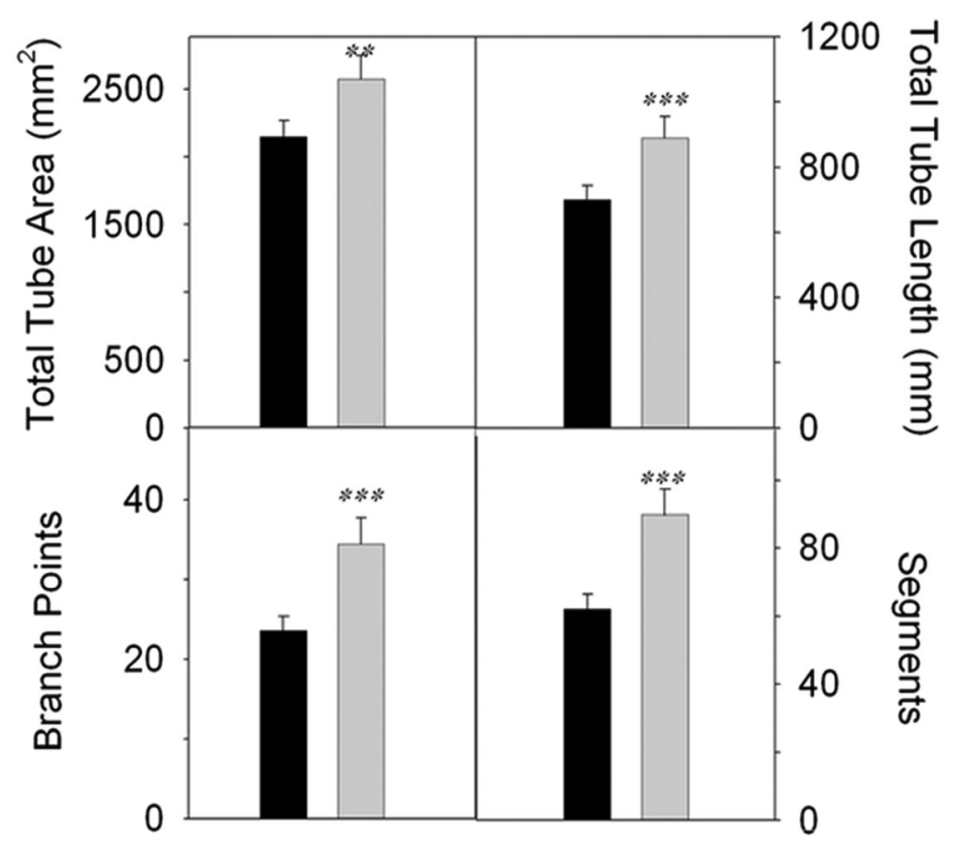

Figure 3. Angiographic evaluation and quantification of neovascularization. (A) Patient with baseline single vessel patency of peroneal artery presented an unexpected finding of fistulous arteriovenous paths (angioma-like structures). (B) Angiographic data of vascular extension (total tube area and length) and vascular density (junction or branch points and vascular segments) at belowthe-knee vascular region were quantified and compared between baseline (black) and 3 months follow-up (gray). There was significant increase of each variable, which expresses the appearance of neovascularization induced by intra-arterial administration of autologous BMMNCs. Statistical significance was assessed by using a paired samples $t$-test (sig. two-tailed). 
tubules length and total tubules area with a paired difference mean of $196.33 \mathrm{~mm}$, sig. 0.00022 (two-tailed), and $444.57 \mathrm{~mm}^{2}$, sig. 0.002 (two-tailed), respectively] and sprouting network [segments and branch point with a paired difference mean of 28.89, sig. 0.00017 (two-tailed) and 11.53, sig. 0.00015 (two-tailed), respectively] (Fig. 3B).

\section{Clinical Changes Induced by BMMNCs}

One year after BMMNCs infusion, there was a remarkable improvement in clinical status in most of the target limbs. All 16 patients who were alive after the first year of follow-up presented with a notable improvement in both Rutherford-Becker and University of Texas classification (Table 2). The University of Texas diabetic wound classification reflected complete healing of trophic lesions without signs of ischemia or infection in every patient, except for one (P9), who presented with a

Table 2. Improvement of Clinical Outcomes After Implant of BMMNCs: Evolution of Rutherford-Becker and University of Texas Classification Before (Baseline) and 3 and 12 Months After

\begin{tabular}{|c|c|c|c|}
\hline & $\begin{array}{c}\text { Baseline } \\
\text { Cases (\%) }\end{array}$ & $\begin{array}{l}3 \text { Months } \\
\text { Cases }(\%)\end{array}$ & $\begin{array}{l}12 \text { Months } \\
\text { Cases }(\%)\end{array}$ \\
\hline \multicolumn{4}{|c|}{$\begin{array}{l}\text { Rutherford-Becker } \\
\text { categories }\end{array}$} \\
\hline Cat. 0 & & 0 & $4(25 \%)$ \\
\hline Cat. 1 & & $5(26.4 \%)$ & $9(56.25 \%)$ \\
\hline Cat. 2 & & $12(63.1 \%)$ & $3(18.75 \%)$ \\
\hline \multicolumn{4}{|l|}{ Cat. 3} \\
\hline Cat. 4 & $3(15 \%)$ & & \\
\hline Cat. 5 & $11(55 \%)$ & $2(10.5 \%)$ & \\
\hline Cat. 6 & $6(30 \%)$ & & \\
\hline \multicolumn{4}{|c|}{ University of Texas } \\
\hline \multicolumn{4}{|c|}{ Stage A } \\
\hline No Ulcer & $1 \quad(5 \%)$ & & \\
\hline A0 & $3(15 \%)$ & $15(79 \%)$ & $14(\mathbf{8 7 . 5} \%)$ \\
\hline A1 & & $2(10.5 \%)$ & $1(6.25 \%)$ \\
\hline $\mathrm{A} 2$ & $1 \quad(5 \%)$ & $1(5.3 \%)$ & \\
\hline \multicolumn{4}{|l|}{ A3 } \\
\hline \multicolumn{4}{|l|}{ Stage C } \\
\hline $\mathrm{C} 0$ & $3(15 \%)$ & & \\
\hline $\mathrm{C} 1$ & $3(15 \%)$ & & \\
\hline $\mathrm{C} 2$ & $3(15 \%)$ & & \\
\hline $\mathrm{C} 3$ & $6(30 \%)$ & & \\
\hline
\end{tabular}

One patient $(5 \%)$ died in the first 3 months and another three $(15 \%)$ in the first 12 months. No more deaths in the population analyzed (16 patients $>24$ months). Rutherford-Becker categories: Cat 0, asymptomatic; Cat 1, mild claudication; Cat 2, moderate claudication; Cat 3, severe claudication; Cat 4, rest pain; Cat 5 , minor tissue loss; Cat 6 , ulceration or gangrene. The University of Texas uses a system of wound grade and stage to categorize wounds by severity. Wounds are graded by depth (grades $0,1,2$, and 3 ). Within each wound grade, there are four stages: clean wounds (A), nonischemic infected wounds (B), ischemic wounds (C), and infected ischemic wounds (D). Values in bold indicate a clear improvement rate in high \% of the population. superficial ulcer (A1) located on the first toe. Referring physicians reported that the infusion of BMMNCs induced an unexpected benefit of an improvement in the healing process, not only for ulcers (Fig. 4B), but even for minor amputations. Furthermore, early clinical benefits of cell infusion consisted of patients having a widespread perception of less limb pain, an increase in painfree walking, and warmness in the target limb. At the 3month follow-up, patients (one deceased, P16) manifested clear clinical benefit, with the exception of two patients (P5 and P11) who also showed no angiographic improvement. In addition to the clinical improvement for the majority of the sample population, there was a significant increase in ABI (from $0.46 \pm 0.19$ to $0.70 \pm$ 0.23 , sig. 0.019) in the target limb at the 3-month follow-up (Fig. 4C) and even more at 12-month follow-up (from $0.46 \pm 0.19$ to $0.81 \pm 0.19$, sig. 0.000). The tcpO increased in most patients and also for those with tcpO $\mathrm{O}_{2}<$ $30 \mathrm{mmHg}(22 \pm 4 \mathrm{mmHg}$ at baseline vs. $40.6 \pm 18.3$ at 3-month follow-up).

During the 1-year follow-up period, there were no major amputations in any patient, even for the nontarget limb. However, 7 patients did undergo minor toe amputations, all of which had Rutherford-Becker categories $(5 / 6)$ at baseline: 5 patients underwent amputations in the target limb (P2, P7, P8, P19: transmetatarsal and P16 chopart's), one underwent an amputation in the nontarget limb (P1) and the other patient (P5) underwent minor bilateral transmetatarsal amputations. All toe amputations, except in one patient (P9, due to shoe trauma that provoked osteomyelitis of the first toe), were scheduled prior to the BMMNC infusion (wet necrosis leading to dry necrosis) and were performed during the first 3 months.

Four patients (P2, P7, P12 and P16) died due to ischemic cardiac disease complications that were unrelated to the cell therapy. The mortality rate in our population (20\%) was similar to that in other studies (2) and was highly dependent on cardiac or cerebrovascular complications (14).

Local neovascularization and clinical improvement in these patients prior to death was similar to the rest of the sample group. No additional deaths were observed after 12 months. Taken together, these results suggest clear clinical and angiographic improvements that result from autologous BMMNC implantation. In 12 patients, we observed that the clinical follow-up benefit matched the angiogenic data at 3 months, whereas in the other patients, the clinical recovery was slower and 3 patients (18.75\%) showed neither angiographic nor clinical improvement and/or the persistence of trophic lesions. Overall agreement between angiography and clinical status at 3 months was observed in approximately $80 \%$ of patients. 
A

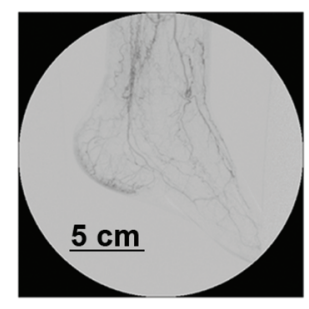

Baseline

B

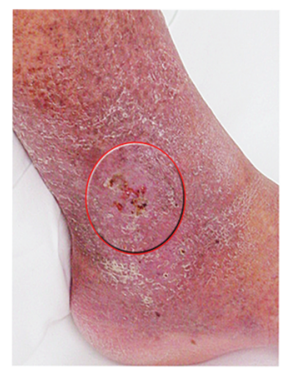

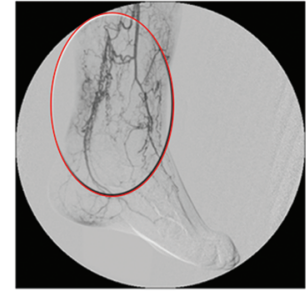

3 months follow-up

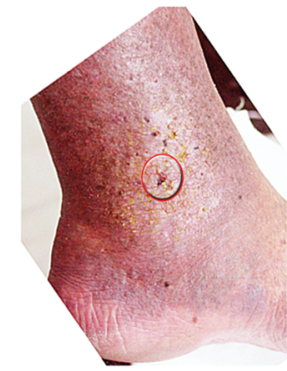

C

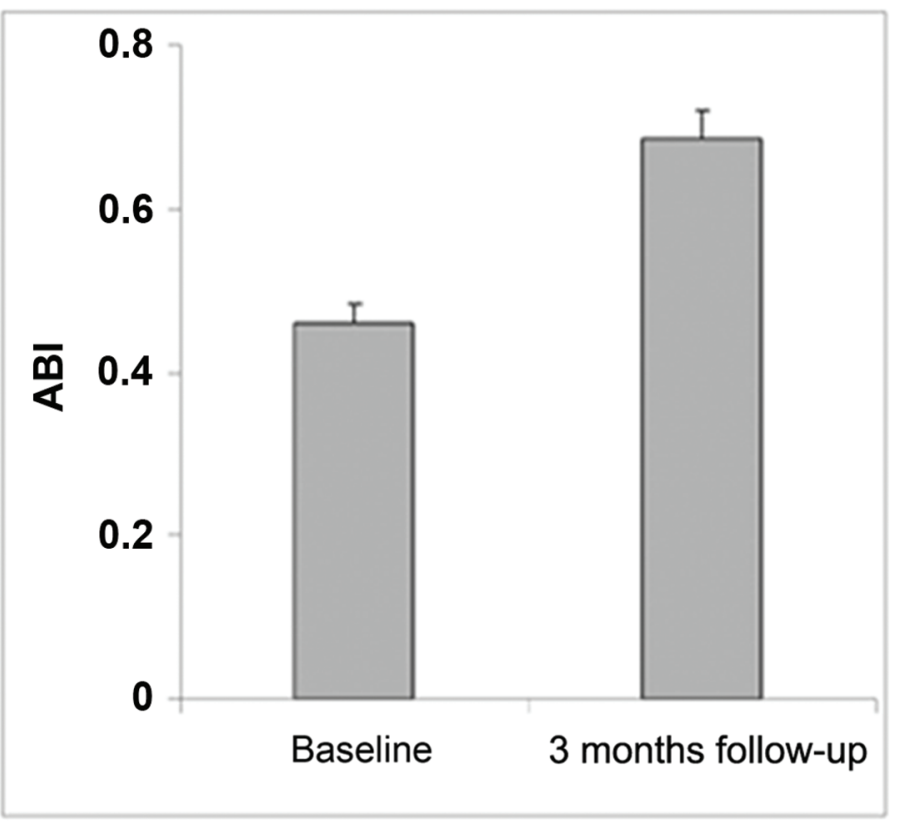

Figure 4. Neovascularisation and clinical correlation. (A) The 3-month angiography showed increased vascular network perfusing (inner circle) the area of trophic lesion, favoring ulcer healing. (B) Baseline unhealed ulcer at inner malleolus improved after autologous BMMNC administration. (C) Average of ankle-brachial index (ABI) showing an increase from $0.46 \pm 0.19$ to $0.70 \pm$ 0.23 of target limb at 3 months. Values are shown as mean \pm SD and statistical significance was performed using paired $t$-test.

\section{Safety Assessment}

No procedural complications during the cell administration were reported: even in low-perfusion areas, the infusion of BMMNCs did not cause any embolic events. During the first year, there were no adverse events directly related to BMMNCs transplantation.

\section{DISCUSSION}

The results of our study strongly suggest that intra-arterial implantation of low doses of autologous BMMNCs into ischemic limbs of diabetic patients induces the development of significant and functional neovascularization. To our knowledge, this is the first study in which the vascular area and vascular density in the ischemic region has been quantified using MetaMorph software. Furthermore, the angiographic improvement observed correlated well with the clinical benefit during the first year of follow-up. Interestingly, 5 patients continued to make notable clinical improvements after 2 years of follow-up.

CLI represents a major concern due to its prevalence among diabetic patients, its poor prognosis, and its limited treatment options $(6,7)$. Surgical or endovascular revascularization options are limited due to the poor arterial outflow in diabetics (14).
In this scenario, the clinical benefits of stem cell therapy have been reported in several studies. The Therapeutic Angiogenesis by Cell Transplantation trial (TACT) was the first study that demonstrated an effective role of the intramuscular administration of BMMNCs for CLI, with a transient (1 month and 6 months) improvement in the severity of rest pain $(21,30)$. Moreover, Amann et al. showed that bone marrow cell transplantation improved leg perfusion and promoted leg salvage in patients with end-stage CLI caused by peripheral artery disease (1). Based on preclinical studies (19), several unresolved issues still remain; these include the ideal type of cells (BMMNCs, CD34 ${ }^{+}$cells, mesenchymal stem cells, combinations) that should be used, the dose and route of administration, and the profile of patients who may receive the greatest benefit.

The main strengths of this study include the following: i) the target population was focused on diabetic patients, whereas other studies recruited patients from different pathologies (Buerger, tromboangeitis obliterans, diabetes mellitus, etc.); ii) intra-arterial administration of BMMNCs that was as distal as possible and was downstream of the diseased arterial bed; iii) the primary endpoint was the angiographic confirmation of neovascularization in ischemic limb areas at the 3-month follow-up, which was quantified by MetaMorph software; and iv) 
the dose used was 10 times smaller $\left(2.66 \pm 0.8 \times 10^{8}\right.$ cells) than the dose $\left(1-5 \times 10^{9}\right.$ cells $)$ used in previous studies $(1,30)$. Recent studies have proved the feasibility and the safety of intra-arterial administration of BMMNCs, single or combined with intramuscular infusion $(3,13$, 33). A recent clinical trial (13) that compared intraarterial BMMNC administration with intramuscular BMMNC administration showed no significant benefit of one of the other; however, there is a trend that favors the intra-arterial route in terms of pain relief and limb salvage. In our study, BMMNCs were infused downstream into lower limb arteries and, for all but one patient, cells were distally infused at the popliteal artery or below while discontinuing antegrade blood flow for 3 min, which guaranteed homing of a greater number of BMMNCs to the ischemic target area.

To date, the assessment of the efficacy of cell therapy in severe PAD was based on surrogate endpoints (relief of pain and decrease of amputation rate) or functional tests $\left(\mathrm{ABI}\right.$ and $\left.\mathrm{tcpO}_{2}\right)$, which reflect the perfusion of the ischemic limb $(1,27)$. None of the previous studies demonstrated neovascularization in diabetic patients with CLI using a quantitative method. Neovascularization may be demonstrated either directly or by angiographic follow-up or through the pathological examination of amputated limb samples (32) that are not obtained from the injection sites. In our study, MetaMorph software enabled the quantification of the vascular tree $(4,10,17)$. The majority of patients presented with a significant increase in vascularity in the ischemic BTK areas after cell infusion; this increase in neovascularization was correlated with the clinical status, with notable symptomatic improvement in the target limb for all at the 1year follow-up. A widespread improvement in Rutherford-Becker grade, ABI, and an almost complete healing of previous diabetic trophic lesions in the lower extremities were observed 3 months and 1 year posttransplantation.

In contrast with other studies in which patients with HbA1cs above $6.5 \%$ were excluded $(13,15,21,30)$, our patients displayed a broad range of $\mathrm{HbA1c}$ values (from $5.7 \%$ to $9.7 \%$ ), which were quite similar to those included in the Amann et al. study (1). This allowed us to test whether the baseline and follow-up value of HbA1c determines the clinical outcome. A direct comparison between the patients with an HbA1c below 6.5\% (P14, $\mathrm{P} 17$, and P19) and those with higher HbA1cs (P3, P9, and P13) demonstrates that this is not the case. In both groups, the HbAlc remained at the baseline values. We observed similar benefits in patients with all levels of HbA1c. However, in those patients with lower HbA1c values, the clinical scores were almost returned to normal levels (ABI from 0.52 to 0.90 ; Rutherford-Becker from categories 5 to 2/0; Texas from $\mathrm{C} 2-\mathrm{C} 1-\mathrm{C} 0$ to $\mathrm{A} 0$; and 4 MethaMorph parameters improved) while patients with higher HbA1c showed a significant improvement (ABI from 0.35 to 0.72 ; Rutherford-Becker categories $5 / 6$ to $1 / 0$; Texas from $\mathrm{C} 2-\mathrm{A} 2-\mathrm{A} 0$ to $\mathrm{A} 1-\mathrm{A} 0$; and $2-3$ MethaMorph parameters improved). These results suggest that functional endothelial progenitors from the bone marrow (presumably devoid of the glycosylation damage) are fully operative in terms of neovascularization. Besides this improvement in the majority of patients, the assessment of ABI also showed a significant increase at the 3-month follow-up compared to baseline.

The appearance of angiomatous structures downstream of the BMMNC perfusion point could be a matter of concern. Vascular endothelial growth factor (VEGF) gene therapy for CLI has been associated with the occurrence of angioma (16). Administration of BMMNCs into severe ischemic tissues with upregulated endothelial receptors to angiogenic cytokines could trigger a hyperactive response in creating new vessels. Three patients presented with angioma-like structures, with high contrast intensity and rapid transition to venous circulation representing increased angiogenesis with low-resistance flow to adjacent venules; luckily these patients experienced no complications. As previously reported, 1-year mortality for patients with severe PAD is approximately $20 \%$ and is mostly dependent on cardiovascular complications $(1,2,14)$. In our study, 4 deaths were registered during the first year. Exitus were due to cardiovascular deaths that occurred at least 3 months after the procedure and were unrelated to BMMNCs therapy. However, there was a significant increase in local neovasculogenesis for the majority of the patient population and the subsequent decrease in the number of amputations (1) and overall mortality was similar to that reported in PAD $(2,14)$.

\section{CONCLUSIONS}

The following conclusions were drawn: 1) intra-arterial transplantation of BMMNCs in diabetic patients with severe PAD is an effective approach that is associated with short-term induction of neovascularization; 2) our population manifested clinical improvement in the lower limb, which included better ulcer healing, increased ABI values, increased leg temperature, and other local signs that are indirect indicators of collateral vessel formation; 3) the dose used is 10 times smaller than that used in previously published studies; 4) intra-arterial BMMNC transplantation is a safe procedure, with no adverse events resulting from stem cell therapy; and 5) diabetic patients with HbA1cs above $6.5 \%$ should not be excluded from these studies or from potential treatment.

ACKNOWLEDGMENTS: We are especially grateful to the patients and their families and the Andalusian Initiative for Advanced Therapies. We thank Dr. Jesús Otero's group from 
Hospital Central of Asturias (University Center Oviedo) for their assistance in performing the bone marrow extraction. The technical assistance from Ma Jesús Fernandez, Yolanda Aguilera, Dr. Susana Garcia, and the CABIMER's GMP facilities staff is greatly appreciated. We thank Dr. Jane Wakeman for critically reviewing this article. The authors are supported by the Fundación Progreso y Salud, Consejería de Salud, Junta de Andalucía (Grant PI-0022/2008), the Ministry of Science and Innovation (Red TERCEL Grant RD06/0010/0025; Instituto de Salud Carlos III Grant PI10/00964), and the Ministry of Health and Consumer Affairs (Advanced Therapies Program Grant TRA-120). CIBERDEM is an initiative of the Instituto de Salud Carlos III. The authors declare no conflicts of interest.

\section{REFERENCES}

1. Amann, B.; Luedemann, C.; Ratei, R.; Schmidt-Lucke, J. A. Autologous bone marrow cell transplantation increases leg perfusion and reduces amputations in patients with advanced critical limb ischaemia due to peripheral artery disease. Cell Transplant. 18(3):371-380; 2009.

2. Barani, J.; Nilsson, J. A.; Mattiasson, I.; Lindblad, B.; Gottsäter, A. Inflammatory mediators are associated with 1-year mortality in critical limb ischaemia. J. Vasc. Surg. 42(1):75-80; 2005.

3. Bartsch, T.; Brehm, M.; Zeus, T.; Kögler, G.; Wernet, P.; Strauer, B. E. Transplantation of autologous mononuclear bone marrow stem cells in patients with peripheral arterial disease (the TAM-PAD study). Clin. Res. Cardiol. 96(12): 891-899; 2007.

4. Blatt, R. J.; Clark, A. N.; Courtney, J.; Tully, C.; Tucker, A. L. Automated quantitative analysis of angiogenesis in the rat aorta model using Image-Pro Plus 4.1. Comput. Methods Programs Biomed. 75(1):75-79; 2004.

5. Boddington, S. E.; Henning, T. D.; Jha, P.; Schlieve, C. R.; Mandrussow, L.; DeNardo, D.; Bernstein, H. S.; Ritner, C.; Golovko, D.; Lu, Y.; Zhao, S.; Daldrup-Link, H. E. Labeling human embryonic stem cell-derived cardiomyocytes with indocyanine green for noninvasive tracking with optical imaging: An FDA-compatible alternative to firefly luciferase. Cell Transplant. 19(1):55-65; 2010.

6. Caputo, G. M.; Cavanagh, P. R.; Ulbrecht, J. S.; Gibbons, G. W.; Karchmer, A. W. Assessment and management of foot disease in patients with diabetes. N. Engl. J. Med. 331(13):854-860; 1994.

7. Ciavarella, A.; Silletti, A.; Mustacchio, A.; Gargiulo, M.; Galaverni, M. C.; Stella, A.; Vannini, P. Angiographic evaluation of the anatomic pattern of arterial obstructions in diabetic patients with critical limb ischaemia. Diabetes Metab. 19(6):586-589; 1993.

8. Crabbe, A.; Vandeputte, C.; Dresselaers, T.; Sacido, A. A.; Verdugo, J. M.; Eyckmans, J.; Luyten, F. P.; Van Laere, K.; Verfaillie, C. M.; Himmelreich, U. Effects of MRI contrast agents on the stem cell phenotype. Cell Transplant. 19(8):919-936; 2010.

9. Cuende, N.; Izeta, A. Clinical translation of stem cell therapies: A bridgeable gap. Cell Stem Cell 6(6):508-512; 2010.

10. Dace, D. S.; Khan, A. A.; Kelly, J.; Apte, R. S. Interleukin-10 promotes pathological angiogenesis by regulating macrophage response to hypoxia during development. PLoS One 3(10):e3381; 2008.

11. Fadini, G. P.; Miorin, M.; Facco, M.; Bonamico, S.; Baesso, I.; Grego, F.; Menegolo, M.; de Kreutzenberg,
S. V.; Tiengo, A.; Agostini, C.; Avogaro, A. Circulating endothelial progenitor cells are reduced in peripheral vascular complications of type 2 diabetes mellitus. J. Am. Coll. Cardiol. 45(9):1449-1457; 2005.

12. Fadini, G. P.; Sartore, S.; Agostini, C.; Avogaro, A. Significance of endothelial progenitor cells in subjects with diabetes. Diabetes Care 30(5):1305-1313; 2007.

13. Gu, Y. Q.; Zhang, J.; Guo, L. R.; Qi, L. X.; Zhang, S. W.; Xu, J.; Li, J. X.; Luo, T.; Ji, B. X.; Li, X. F.; Yu, H. X.; Cui, S. J.; Wang, Z. G. Transplantation of autologous bone marrow mononuclear cells for patients with lower limb ischaemia. Chin. Med. J. 121(11):963-967; 2008.

14. Hirsch, A. T.; Haskal, Z. J.; Hertzer, N. R.; Bakal, C. W.; Creager, M. A.; Halperin, J. L.; Hiratzka, L. F.; Murphy, W. R. C.; Olin, J. W.; Puschett, J. B.; Rosenfield, K. A.; Sacks, D.; Stanley, J. C.; Taylor, L. M.; White, C. J.; White, J.; White, R. A. ACC/AHA 2005 practice guidelines for the management of patients with peripheral arterial disease (lower extremity, renal, mesenteric, and abdominal aortic). Circulation 113(11):1474-1547; 2006.

15. Huang, P.; Li, S.; Han, M.; Xiao, Z.; Yang, R.; Han, Z. Autologous transplantation of granulocyte colony-stimulating factor-mobilized peripheral blood mononuclear cells improves critical limb ischaemia in diabetes. Diabetes Care 28(9):2155-2160; 2005.

16. Isner, J. M.; Pieczek, A.; Schainfeld, R.; Blair, R.; Haley, L.; Asahara, T.; Rosenfield, K.; Razvi, S.; Walsh, K.; Symes, J. F. Clinical evidence of angiogenesis after arterial gene transfer of phVEGF165 in patient with ischaemic limb. Lancet 348(9024):370-374; 1996.

17. Lacher, S.; Devy, L.; Burbridge, M. F.; Roland, G.; Tucker, G.; Noël, A.; Foidart, J. M. Improved quantification of angiogenesis in the rat aortic ring assay. Angiogenesis 4(2): 133-142; 2001.

18. Lavery, L. A.; Armstrong, D. G.; Harkless, L. B. Classification of diabetic foot wounds. J. Foot Ankle Surg. 35(6): 528-531; 1996.

19. Lawall, H.; Bramlage, P.; Amann, B. Stem cell and progenitor cell therapy in peripheral artery disease. A critical appraisal. Thromb. Haemost. 103(4):696-709; 2010.

20. Loomans, C. J.; de Koning, E. J.; Staal, F. J.; Rookmaaker, M. B.; Verseyden, C.; de Boer, H. C.; Verhaar, M. C.; Braam, B.; Rabelink, T. J.; van Zonneveld, A. J. Endothelial progenitor cell dysfunction: A novel concept in the pathogenesis of vascular complications of type 1 diabetes. Diabetes 53(1):195-199; 2004.

21. Matoba, S.; Tatsumi, T.; Murohara, T.; Imaizumi, T.; Katsuda, Y.; Ito, M.; Saito, Y.; Uemura, S.; Suzuki, H.; Fukumoto, S.; Yamamoto, Y.; Onodera, R.; Teramukai, S.; Fukushima, M.; Matsubara, H.; TACT Follow-up Study Investigators. Long-term clinical outcome alter intramuscular implantation of bone marrow mononuclear cells (Therapeutic Angiogenesis by Cell Transplantation [TACT] trial) in patients with chronic limb ischaemia. Am. Heart J. 156(5):1010-1018; 2008.

22. Nohroudi, K.; Arnhold, S.; Berhorn, T.; Addicks, K.; Hoehn, M.; Himmelreich, U. In vivo MRI stem cell tracking requires balancing of detection limit and cell viability. Cell Transplant. 19(4):431-441; 2009.

23. Norgren, L.; Hiatt, W. R.; Dormandy, J. A.; Nehler, M. R.; Harris, K. A.; Fowkes, F. G.; TASC II Working Group. Inter-society consensus for the management of peripheral arterial disease (TASC II). J. Vasc. Surg. 45(Suppl. S):S5-67; 2007. 
24. Richard, P. L.; Gosselin, C.; Laliberté, T.; Paradis, M.; Goulet, M.; Tremblay, J. P.; Skuk, D. A first semimanual device for clinical intramuscular repetitive cell injections. Cell Transplant. 19(1):67-78; 2010.

25. Rüger, L. J.; Irnich, D.; Abahji, T. N.; Crispin, A.; Hoffmann, U.; Lang, P. M. Characteristics of chronic ischemic pain in patients with peripheral arterial disease. Pain 139(1):201-208; 2008.

26. Rutherford, R. B.; Baker, J. D.; Ernst, C.; Johnston, K. W.; Porter, J. M.; Ahn, S.; Jones, D. N. Recommended standards for reports dealing with lower extremity ischaemia. Revised version. J. Vasc. Surg. 26(3):517-538; 1997.

27. Saigawa, T.; Kato, K.; Ozawa, T.; Toba, K.; Makiyama, Y.; Minagawa, S.; Hashimoto, S.; Furukawa, T.; Nakamura, Y.; Hanawa, H.; Kodama, M.; Yoshimura, N.; Fujiwara, H.; Namura, O.; Sogawa, M.; Hayashi, J.; Aizawa, Y. Clinical application of bone marrow implantation in patients with arteriosclerosis obliterans, and the association between efficacy and the number of implanted bone marrow cells. Circ. J. 68(12):1189-1193; 2004.

28. Sanchez-Guijo, F. M.; Oterino, E.; Barbado, M. V.; Carrancio, S.; Lopez-Holgado, N.; Muntion, S.; HernandezCampo, P.; Sanchez-Abarca, L. I.; Perez-Simon, J. A.; San Miguel, J. F.; Briñon, J. G.; del Cañizo, M. C. Both $\mathrm{CD}_{133^{+}}$cells and monocytes provide significant improvement for hindlimb ischaemia, although they do not transdifferentiate into endothelial cells. Cell Transplant. 19(1): 103-112; 2010.
29. Schaper, W.; Buschmann, I. Collateral circulation and diabetes. Circulation 99(17):2224-2226; 1999.

30. Tateishi-Yuyama, E.; Matsubara, H.; Murohara, T.; Ikeda, U.; Shintani, S.; Masaki, H.; Amano, K.; Kishimoto, Y.; Yoshimoto, K.; Akashi, H.; Shimada, K.; Iwasaka, T.; Imaizumi, T.; Therapeutic Angiogenesis using Cell Transplantation (TACT) Study Investigators. Therapeutic angiogenesis for patients with limb ischaemia by autologous transplantation of bone-marrow cells: A pilot study and a randomised controlled trial. Lancet 360(9331):427-435; 2002.

31. Tepper, O. M.; Galiano, R. D.; Capla, J. M.; Kalka, C.; Gagne, P. J.; Jacobowitz, G. R.; Levine, J. P.; Gurtner, G. C. Human endothelial progenitor cells from type II diabetics exhibit impaired proliferation, adhesion, and incorporation into vascular structures. Circulation 106(22):27812786; 2002.

32. Van Huyen, J. P.; Smadja, D. M.; Bruneval, P.; Gaussem, P.; Dal-Cortivo, L.; Julia, P.; Fiessinger, J. N.; CavazzanaCalvo, M.; Aiach, M.; Emmerich, J. Bone marrow-derived mononuclear cell therapy induces distal angiogenesis after local injection in critical leg ischaemia. Mod. Pathol. 21(7):837-846; 2008.

33. Van Tongeren, R. B.; Hamming, J. F.; Fibbe, W. E.; Van Weel, V.; Frerichs, S. J.; Stiggelbout, A. M.; Van Bockel, J. H.; Lindeman, J. H. Intramuscular or combined intramuscular/intra-arterial administration of bone marrow mononuclear cells: A clinical trial in patients with advanced limb ischaemia. J. Cardiovasc. Surg. 49(1):51-58; 2008. 
